
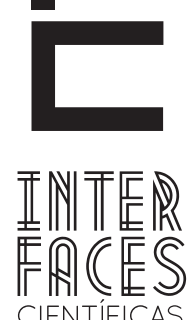

HUMANASE SOCIAIS

ISSN IMPRESSO 2316-3348

E-ISSN 2316-3801

DOI - 10.17564/2316-3801.2018v7n2p131-154

\title{
A QUESTÃO DOS DIREITO DA NATUREZA NO VIÉS DA JUSTIÇA ECOLÓGICA: QUAL A TUTELA JURÍDICA A SER BUSCADA?
}

THE QUESTION OF NATURE LAW IN THE EVENT OF ECOLOGICAL JUSTICE: WHAT IS THE LEGAL GUARD TO BE SEARCHED FOR?

\section{LACUESTIÓN DE LOS DERECHOS DELA NATURALEZA ENEL RAMO DE LA JUSTICIA ECOLÓGICA: ¿quÁL ES LA TUTELA JURíDICA A SER BUSCADA?}

\section{RESUMO}

Esta pesquisa tem por objetivo analisar o Direito da Natureza a partir da questão ecológica dos direitos humanos no viés da Justiça Ecológica como realidade possível. Diante dessas categorias indaga-se: de que modo é possível concretizar o Direito da Natureza, como ser próprio e sujeito de direitos? Aponta-se que para restabelecer as relações de respeito com a Natureza e com complexidade da vida que sustenta os biomas, é necessário mudar valores preestabeleci- dos, ou seja, o formato hoje dominante do homem de competição predatória e incluir o mudar que requer ampliar a atitude de libertação no modo que reside do agir, do pensar, da ética, na desaceleração da entropia e ampliar as redes comunitárias de sustentabilidade.

\section{PALAVRAS-CHAVE}

Justiça Ecológica. Direitos Humanos. Direito da Natureza. 


\section{ABSTRACT}

This research aims to analyze the Right of the Nature of the ecological issue of Human Rights in the bias of ecological justice as a possible reality. Taking these categories into account, he asks: How can you achieve the a Right of Nature, as your own and subject of rights? He points out that in order to restore relations of respect to the nature and complexity of life that sustains the biomes, it is necessary to change pre-established values, thus, the format of today is the dominant man of predatory com- petence and include the change that requires Extending the attitude of liberation lies in the act of thinking, ethics, the deceleration of entropy and expanding the networks of the sustainability community.

\section{KEYWORDS}

Ecological Justice. Human Rights. Rights of Nature.

\section{RESUMEN}

Esta investigación tiene por objetivo analizar el Derecho de la Naturaleza a partir de la cuestión ecológica de los derechos humanos bajo el punto de vista de la Justicia Ecológica como realidad posible. Ante estas categorías se indaga: ¿de qué modo y posible concretar el Derecho de la Naturaleza, como ser propio y sujeto de derechos? Se apunta que para restablecer las relaciones de respeto con la naturaleza y con complejidad de la vida que sostiene los biomas, es necesario cambiar valores preestablecidos, o sea, el formato hoy dominante del hombre

de competencia predatoria e incluir el cambio que requiere ampliar la actitud de liberación en el modo que reside del actuar, del pensar, de la ética, en la desaceleración de la entropía y ampliar las redes comunitarias de sustentabilidad.

\section{PALABRAS CLAVE}

Justicia ecológica; Derechos humanos; Derecho de la naturaleza; 


\section{INTRODUÇ̃̃O}

Atualmente, a realidade ecológica global encontrase ameaçada pela conduta humana, que vem alterando o ecossistema e que dele depende para sua sobrevivência. Em que pese o fato de diversos movimentos sociais sustentarem a necessidade da adoção de novas normas de conduta, que evitem a ação destrutiva social e ecológica que sofre a humanidade, os desafios ainda estão longe de ser superados. A agenda política internacional já inaugurou, em 1970, ações no sentido de efetivar o princípio da sustentabilidade.

No entanto, os avanços conquistados não foram capazes de alterar a situação de crise, fato que enseja reflexão, debate e discussão sobre direitos da natureza, justiça ecológica e direitos humanos. Nesta pesquisa, o objetivo é, a partir dos pressupostos teóricos sobre o tema, buscar alternativas que esclareçam não apenas o significado da Justiça Ecológica como paradigma da vida e dignidade para todos os seres, mas como esse fenômeno manifesta na dimensão jurídica, como realidade possível ao direito da natureza a partir da questão ecológica dos direitos humanos.

Nessa linha de pensamento, não é possível mais insistir somente numa Justiça Social, mas numa Justiça Ecológica, como paradigma que encontra suas raízes no pensamento, na consciência e na reflexão ética da humanidade, na ampliação da justiça no âmbito ecológico e, permitir o reconhecimento dos limites do ecossistema, em determinar uma nova conduta humana e um novo rumo frente a uma sociedade mais democrática e sustentável. Sem a pretensão de solucionar os problemas vivenciados pela sociedade no tocante a crise ambiental, as presentes linhas objetivam lançar novos questionamentos e reflexões sobre o tema e sugerir alternativas viáveis à concretização da Justiça Ecológica a partir do que dispõe do princípio da Sustentabilidade, numa perspectiva intergeracional.

Desde já, sustenta-se que a categoria Justiça Ecológica corresponde à função de coordenação de valores, o que possibilita a reelaboração e a reno- vação dos programas políticos e sua transformação em âmbito jurídico. Esse caminho, nos regimes democráticos representa a forma para transformar os conteúdos da justiça e estruturas que dizem respeito a efetivação dos direitos humanos, no seu sentido mais amplo. A importância da função que realiza a Justiça Ecológica em determinar a reponsabilidade da comunidade humana e seu conjunto pelos danos ambientas, face as necessidades de uma distribuição mais justa, implica na reparação da desigualdade ecológica e destruição do mundo natural.

Ainda, a Justiça Ecológica tem como pressuposto a justiça social, para que a espécie humana usufrua 0 meio ambiente adequado e, como base no interesse natural pelo espaço vital, um solo fértil, ar puro, águas limpas, dentre outros. Estes interesses são justificativas morais e jurídica que se encontram também nos direitos humanos e da solidariedade, limitados nos recursos naturais disponíveis a favor de uma conservação e uma relação de reciprocidade como igualdade de oportunidade na dimensão de responsabilidade coletiva, permitindo que cada geração seja capaz de dispor da casa comum chamada Terra.

Diante desse cenário busca-se analisar: de que modo é possível concretizar o Direito da Natureza, como ser próprio e sujeito de direitos? Aponta-se que para restabelecer as relações de respeito com a $\mathrm{Na}$ tureza e com complexidade da vida que sustenta os biomas, é necessário mudar valores preestabelecidos, ou seja, o formato hoje dominante do ser humano de competição predatória e incluir novas perspectivas, como ampliar práticas de libertação, pensamento e ética, em prol da desaceleração da entropia e das redes comunitárias de sustentabilidade.

No mesmo viés, a realização de uma sustentabilidade ecológica é necessária no reconhecimento do direito da natureza sadia que é o direito básico para as gerações atuais e futuras, adotando as ferramentas jurídicas processuais que permitam o exercício jurisdicional. Eis o objetivo deste artigo: refletir sobre o desafio da Justiça Ecológica, numa perspectiva de realização de direitos, não como discurso vazio e abstrato, mas no próprio da vida na 
qual, silenciosamente, se modifica, para assegurar estabilidade e preservar toda a teia da vida. 0 estudo utiliza como critério metodológico para o relato dos resultados apresentados, o método dedutivo, assim como as técnicas de pesquisa bibliográfica ${ }^{3}$ e da categoria ${ }^{4}$.

\section{JUSTIÇA ECOLÓGICA}

Inicialmente, busca-se contextualizar e debater a ideia de Justiça a partir das relações entre indivíduo e Natureza. A Justiça, neste viés, é necessária para balizar as ações humanas na realização de um bem-estar social e ambiental, direcionada a humanos e não humanos. Nesse sentido, o ser humano é capaz de canalizar seus esforços para que a crise planetária, no que diz respeito à natureza, seja superada, a partir da adoção de um modelo de desenvolvimento sustentável e de um agir ético a respeito dos elementos que integram esse mundo. Com cuidado, busca-se o aprimoramento da ideia de justiça ecológica, tanto em relação à expansão das liberdades quanto à conquista do bem comum supremo, a felicidade que para Aristóteles (1999, p. 26.)

Requer bens exteriores, pois é impossível, ou na melhor das hipóteses não é fácil, praticar belas ações sem os instrumentos próprios. Em muitas ações usamos amigos e riquezas e poder político com instrumentos, e há certas coisas cuja falta empana a felicidade - boa estirpe, bons filhos, beleza - pois o Homem de má aparência, ou malnascido, ou só no mundo e sem filhos, tem poucas possibilidades de ser feliz, e tê-las-á ainda menores se seus filhos e amigos forem irremediavelmente maus ou se, tendo tido bons filhos e amigos, estes tiverem morrido. Como dissemos, então, a felicidade parece requerer o complemento desta ventura e é por isto que algumas pessoas identificam a felicidade com a boa sorte, embora outras a identificam com a excelência.

3 “[...] Técnica de investigação em livros, repertórios jurisprudenciais e coletâneas legais" (PASOLD, 2011, p.207).

4 "[...] palavra ou expressão estratégica à elaboração e/ou expressão de uma ideia" (PASOLD, 2011, p. 25).
A justiça ecológica é vetor para a valorização da vida, no seu sentido mais amplo, concretizada por meio do agir humano ético, que respeite o mundo natural e seus ciclos regenerativos, a fim de mitigar as ações que exploram, desmedidamente, a natureza e reconheçam a importância do mundo natural, para além de uma concepção antropológica neste mundo. A categoria remete para as relações entre humanos e natureza, haja vista que as teorias sobre justiça têm sido insuficientes, na compreensão da dimensão real da problemática ambiental.

As condutas humanas nas decisões relevantes ao meio ambiente implicam na importância fundamental e na equidade do comportamento e responsabilidade, para superar a divisão que considera o humano como sujeito e o mundo natural como objeto. Esta dinâmica tem alterado o ecossistema, o que demanda a participação no processo de adotar novas normas de condutas. Não por outra razão que a justiça ecológica busca o equilíbrio acerca do uso desmedido e irresponsável dos elementos naturais que não são, meramente, objetos destinados à utilização humana, sem qualquer forma de zelo ou comprometimento.

Chama atenção à necessidade de adequar a semântica e os significados daquilo que uns chamam de justiça ambiental e outros, de justiça ecológica. Bosselmann (2015) esclarece que há diferenciação entre essas expressões: a primeira diz respeito a justiça da distribuição entre o meio ambiente e os seres humanos e a segunda diz respeito a ideia de justiça das relações entre os humanos e o mundo natural. Para o autor, a justiça ecológica se refere ao tratamento digno e justo para humanos e não humanos na qual o cidadão, por meio dos seus comportamentos e responsabilidades, vivencie a interdependência necessária com o meio ambiente natural, para além dos fenômenos da globalização, da transnacionalidade ou do mercado (BOSSELMANN, 2015).

Para Giménez (2016, p. 19),

La justicia ecológica significa una síntesis superadora del antropocentrismo hacia el ecocentrismo, que reconoce la realidad ontológica y existencial del sujeto humano como centro que integra la expresión de la es- 
pecie humana en la integridad absoluta de sus naturales implicaciones ecosistémicas, sin menoscabo de su traducción virtual o parcial en los derechos humanos y fundamentales en cuanto tales. ${ }^{5}$

Desse modo, a categoria tem por objetivo redimensionar a relação entre natureza e os seres humanos, orientada pelos princípios da sustentabilidade, conservação, responsabilidade e igualdade. Estes princípios, diferenciadores são condutores da ordem política e jurídica do meio ambiente e servem como guia na atividade compartilhada entre Estado e a comunidade transnacional e nacional, que ajuda na desaceleração da entropia e na ampliação da interação ecológica. Para Bosselmann (2015, p. 18-19):

E enquanto pode vir a ser um erro, salta aos olhos que nossa sobrevivência depende da habilidade de manter e respeitar a integridade ecológica da Terra. Essa é a ideia principal do princípio da Sustentabilidade [...] A Sustentabilidade pode ser definida como o princípio fundamental da lei e da Governança. Ela atingiu um grau de maturidade que permite a análise de seu significado e status legal. Isso pode ser feito de modo similar ao que ocorre com outros princípios fundamentais como justiça e liberdade quando foram examinados e promovidos[...] a Sustentabilidade é um conceito geral e deve ser aplicado do mesmo modo que outros conceitos gerais como liberdade, igualdade e justiça.

A crise ambiental enfrentada nesse século e agravada nas últimas décadas sinaliza a necessidade de se refletir sobre a harmonização da relação entre o homem e a natureza a partir da justiça e do direito. A respeito do papel que o Direito, como saber social, pode desempenhar nesta tarefa, cabe mencionar que instrumentos e mecanismos políticos-jurídicos são invocados na defesa e na proteção do meio ambiente. No sentido de superar as desigualdades, pois ao homem, todos os direitos; à natureza, nenhum -, já existem diplomas legais que elevam os elementos que compõe a natureza no patamar de sujeitos de direitos.

5 "A justiça ecológica significa uma síntese de superação do antropocentrismo para o ecocentrismo, que reconhece a realidade ontológica e existencial do sujeito humano como um centro que integra a expressão da espécie humana na integridade absoluta do seu natural. Implicações do ecossistema, sem prejuízo da sua tradução virtual ou parcial nos direitos humanos e fundamentais, como tais."
Como explica Gussoli (2005, on-line),

Um primeiro passo é superar as barreiras que impedem a consideração teórica séria dos direitos da Natureza é separá-la da doutrina dos direitos dos animais. A partir da distinção justiça ambiental (voltada aos seres humanos) e justiça ecológica (voltada ao meio ambiente natural). Alberto Acosta explica que a consideração do valor intrínseco da Natureza e o reconhecimento de sua personalidade jurídica não tem como consequência a proibição do cultivo de plantas, a criação de animais ou mesmo a pesca. Pode-se comer qualquer tipo de carne ou grão, ora a própria manutenção da vida exige a cadeia alimentar. Os direitos da Natureza, portanto, representam um interesse maior que é a manutenção do ecossistema. [...] a justiça ecológica, então, não defende uma natureza intocada, mas sim uma natureza preservada em seus conjuntos de vida.

Esse novo cenário, onde a natureza é “ser próprio”, é também uma manifestação da justiça ecológica, especialmente na possibilidade de se inverter a lógica da destruição do mundo natural, a partir dos critérios de sustentabilidade. A categoria sinaliza para uma perspectiva que possibilita condições adequadas para se estabelecer um vínculo harmônico e equilibrado entre homem e natureza, por meio do desenvolvimento sustentável.

Para Boff (2014, p. 11) “[...] simultaneamente a grande transformação da sociedade de mercado criou também uma iniqua injustiça ecológica. No afã de acumular foram explorados de forma predatória bens e recursos da natureza”, ocasionou um desequilíbrio do ecossistema, pois aprofundou as desigualdades e desencadeou uma crise que sinaliza para a perda de valores essenciais na relação entre homem e natureza. Por esse motivo, é tão importante destacar a justiça ecológica como categoria a ser vivenciada cotidianamente.

A justiça, nestes moldes, sinaliza para o afastamento dos comportamentos de interesses exclusivamente particulares, pois a Justiça adquire um valor moral que integra a ciência jurídica. Sob essa ótica, Boff (2014) destaca que humanidade é uma expressão da Terra, a sua porção consciente, inteligente e responsável pela preservação das condições que continuamente produzem e reproduzem a vida. Contudo, 
o momento presente desvela um esvaziamento ético em relação à Justiça, pois, em seu viés ambiental, o destinatário único é o ser humano.

A sociedade está vivendo uma crise de valores sem precedentes e, diante da desertificação daquilo que é caro à sociedade, há interferência direta no agir humano e na forma com que este se relaciona com o meio em que vive (PELLENZ, 2015). A partir do antropocentrismo a dinâmica é simples: o que não é humano, pela sua condição intrínseca, acaba sendo "coisificado" e figura como bem à disposição da humanidade.

Nesse sentido, Arizio (2017) expõe que a justiça ecológica é vetor para a valorização da vida, no seu sentido mais amplo, concretizada por meio do agir humano ético, que respeite o mundo natural e seus ciclos regenerativos, a fim de mitigar as ações que exploram, desmedidamente, a Natureza e reconheçam a importância do mundo natural, para além de uma concepção antropológica neste mundo. A categoria remete para as relações entre humanos e Natureza, haja vista que as teorias sobre Justiça têm sido insuficientes, na compreensão da dimensão real da problemática ambiental. Nesta toada, no próximo tópico terá destaque o viés ecológico dos direitos humanos, uma reflexão com a proteção aos direitos humanos e proteção aos direitos da natureza, tendo em vista a necessária proporcionalidade para melhores condições de vida conducentes a alcançar a sustentabilidade ecológica.

\section{VIÉS ECOLÓGICO DOS DIREITOS HUMANOS: O DIREITO EM FOCO}

A adoção da Declaração Universal dos Direitos do Homem de 1948 foi a conquista mais importante em relação aos direitos humanos no decorrer da história. No entanto, cabe salientar que tal declaração de direitos foi idealizada para fornecer linhas orientadoras apenas, não pragmaticamente normativas. Nessa qualidade, os direitos fundamentais eram, em primeiro lugar, dirigidos ao legislador. Deste modo, segundo Grimm (2007) sua primeira função foi guiar os legisla- dores na adaptação do sistema legal aos novos princípios. Isto, pelo fato de resguardar a dignidade humana no centro de seus valores, dando a cada indivíduo seu direito de liberdade e de igualdade. Nesse sentido destaca Sarlet (1988, p. 41-42):

\begin{abstract}
A dignidade humana está, portanto, compreendida como qualidade integrante e irrenunciável da própria condição humana, pode (e deve) ser reconhecida, respeitada, promovida e protegida, não podendo, contudo (no sentido ora empregado) ser criada, concedida ou retirada (embora possa ser violada), já que existe em cada ser humano como algo que the é inerente.
\end{abstract}

Salienta Bosselmann (2010) que a proteção dos direitos humanos surgiu do reconhecimento das liberdades após $2^{a}$ Guerra Mundial, o que não ocorreu com os direitos relacionados ao meio ambiente, que surgiram do reconhecimento da existência de uma crise ecológica global na Conferência de Estocolmo em 1972. Desses pactos, os direitos humanos limitaram a soberania dos Estados, não podendo se eximir da obrigação fundamento de proteção a vida, medida que reflete uma regra necessária, o mesmo poderia ser considerado ao meio ambiental.

Em certo ponto, o bem-estar individual e coletivo, como possa parecer, busca-se na concretização dos direitos humanos fundamentais a partir da tutela dos direitos ambientais, indispensáveis a vida humana. Ainda que uma pequena perspectiva difusa, o desenvolvimento humano, em todas as suas dimensões, pode ser conquistado a partir da proteção do mundo natural, independente dos limites geográficos do Estado-nação, como forma de efetivação do paradigma da sustentabilidade. Na medida em que a crise não se limita a um determinado grupo ou território, a crise é generalizada e socializada por todos que são parte integrante de um lar compartilhado chamado Planeta Terra.

A despeito do direito ambiental não ser derivado de uma norma objetiva, sua existência reflete de uma concepção indispensável, sentido de que a proteção da vida e dignidade humana, ou seja, a proteção ao meio ambiente tem como pressuposto básico a preocupação com a vida. Afirma Pellenz (2015, p. 60) 
As responsabilidades são de todos, acerca dos problemas naturais e o acesso democrático aos benefícios do desenvolvimento também deveria o ser. São necessárias ações com vistas na solidariedade e de sobrevivência conjunta. A defesa ambiental, a partir de uma perspectiva solidária, é um passo importante na superação da crise e um reflexo de que o gênero humano não mais é um detentor da Natureza, mas sim, parte integrante dela.

Os seres humanos em termos jurídicos encontram-se intimamente atrelados às tarefas do Estado, pois, a este, justamente, cabe o dever de zelo pela adequada satisfação das necessidades dos humanos tanto individuais e como da coletividade sob sua égide, pois em termos político-jurídico, os seres humanos possuem maior valoração em relação ao meio ambiente como objeto de proteção. Ressalta Bosselmann (2010, p. 77)

Sempre quando ocorre um dano ambiental, o gozo dos direitos humanos está potencialmente em perigo. Uma situação padrão é, por conseguinte, a exposição de indivíduos à poluição do ar, a água contaminada ou as substâncias químicas poluentes. Neste caso, a abordagem dos direitos humanos é "francamente antropocêntrica”, mas pode afetar um amplo espectro de direitos humanos reconhecidos. 0 argumento básico é que o meio ambiente não deve se deteriorar a tal ponto que o direito à vida, o direito à saúde e ao bem-estar, o direito à família e à vida privada, o direito à propriedade e outros direitos humanos fiquem gravemente comprometidos.

Conforme assinala Sampaio (2013), as positivações dos direitos humanos nas constituições contemporâneas visam possibilitar melhores condições de vida sadia, a fim de igualar as situações sociais e as dimensões do ser humano nos direitos humanos e fundamentais, que incidem positivamente e são proporcionadas pelo Estado direta ou indiretamente. Portanto, a saúde ambiental e a saúde humana devem ser consideradas como integrantes do direito a condições de vida sadia, perspectiva em que se as ameaças à dignidade a vida humana terão de ser consideradas violações, a exemplo do aquecimento global e das zonas mortas dos oceanos, nesse mesmo patamar, são violações aos direitos da natureza.
Assim, ideais sinalizam à responsabilidade humana na relação à natureza, como um projeto a ser construído cotidianamente, no sentido que a humanidade é a única que tem consciência para reconhecer e respeitar a moralidade de direitos como parte integrante da natureza que são indissociáveis. Os direitos humanos ecológicos, tem por objetivo vincular os valores intrínsecos humanos e não humanos, como forma de assumir uma responsabilidade com seus pares, fator determinante na relação dos seres humanos e mundo natural.

\section{DIREITO DA NATUREZA}

Os problemas ambientais acerca das limitações da Natureza impõem a necessidade de estratégias as quais se fundamentam pelo desenvolvimento sustentável. Essa compreensão exige um grau de maturidade na participação ativa das pessoas e, é fundamental para a manutenção de todos que habitam o Planeta. Não basta considerar somente as Constituições, Tratados e as Declarações, mas principalmente os atores globais que detém a forma para impulsionar o social e a política com o objetivo de resolver, pacífica e consensualmente os conflitos existentes.

No entanto, para pensar em desenvolvimento sustentável, é necessário, antes, compreender a importância da Sustentabilidade. Essa expressão designa, para fins desta pesquisa, a compreensão acerca da capacidade de resiliência entre os seres e o ambiente para se determinar - de modo sincrônico e/ou diacrônico -, e, ainda, quais são as condições favoráveis à manutenção, adaptação e perpetuação da vida equilibrada, seja humana ou não humana, a partir de uma matriz ecosófica (o ambiental, o das relações humanas e o da subjetividade humana) que se manifesta pelos critérios biológicos, químicos, físicos, informacionais, éticos, territoriais, culturais, jurídicos, políticos, tecnológicos, científicos, ambientais e econômicos. Além disso, a sustentabilidade também denota uma condição transgeracional, a exemplo do disposto no artigo 225 da Constituição Federal. 
Para concretização da sustentabilidade, como princípio e como direito, apresenta-se a expressão "atores globais" em dimensão ecocêntrica e biocêntrica, a qual não se destaca tão somente as qualidades dos seres humanos, a sua racionalidade e sua capacidade de organização e modificação do Planeta Terra, porém identifica e considera como cada ser vivo contribui, de modo próprio, na manutenção das condições apropriadas ao desenvolvimento da vida, no seu sentido mais amplo. A busca pela Sustentabilidade, o esclarecimento de sua necessidade e aperfeiçoamento, somente se inicia por essa cumplicidade de todos os seres com a Terra.

Na medida em que for exercida a conscientização frente à Sustentabilidade, de matriz ecológica, projeta-se as necessidades de se evitar a degradação dos ecossistemas. Para Lourenço e Oliveira (2012) decorre que a construção de objetivos para um desenvolvimento sustentável irá viabilizar e fortalecer as capacidades que irão construir a sustentabilidade no âmbito ecológico, resultando num bem-estar para os seres humanos.

No entanto, há um desafio quanto a sustentabilidade ecológica no que se refere à conscientização individual das atitudes humanas, na qual pressupõe um compromisso necessário e dialógico entre indivíduo e mundo natural. Busca-se por meio da preservação e utilização responsável dos bens naturais disponíveis, a possibilidade de sobrevivência das presentes e futuras gerações, num viés biocêntrico. Essas são as adversidades do século XXI, pois as mudanças para um mundo mais sustentável e justo devem respeitar as diferenças culturais e naturais, o que é um passo desafiador num mundo heterogêneo. Nessa mesma linha de pensamento, Acosta (2016) argumenta:

Tal estilo de vida consumista e predador não apenas coloca em risco o equilíbrio ecológico global, mas marginaliza cada vez mais massas de seres humanos das (supostas) vantagens do ansiado desenvolvimento. Apesar dos indiscutíveis avanços tecnológicos, onde nem a fome foi erradicada do planeta.

Cruz e Bodnar (2012) são enfáticos em suas constatações de que na atual sociedade global, o equilíbrio ecológico não será o mesmo. Os autores advertem que se vive um momento crítico no qual o Planeta suportou todos os limites, como, por exemplo, o desrespeito humano ao tempo próprio dos ciclos regenerativos da Terra, o aumento da pobreza, a má governança dos bens comuns, especialmente aqueles nos quais se referem ao mundo natural, a insistência histórica do modelo capitalista em criar, mais e mais, marginalizados, fatores que consolidam individualismo o desapego com o Outro a aparência de se buscar uma qualidade de vida para uma determinada nação às custas de outros países, dentre mais fatores.

Percebe-se, a partir das palavras de Morin (2010, p. 34) que "[...] tudo, neste mundo, está em crise. Dizer crise é afirmar - já o vimos anteriormente - progressão das incertezas". A ação humana traz impactos ao meio ambiente natural e artificial, ao dominar, explorar e subjugar os limites de todos os seres vivos. Traduz o autor, da melhor forma as síndromes atuais do nosso planeta "[...] o planeta vive, cambaleia, gira, arrota, soluça, geme sem contar com o amanhã. Tudo é feito, vivido, a curto prazo".

Esse contexto, acumulativo de intenso e desmedido abuso da Natureza eram previsíveis, ou seja, não podendo diagnosticar como uma surpresa, pois houve permissão do homem para as catástrofes, a Natureza vem sofrendo e as consequências surgem sobretudo porque foram construídas a partir de um desenvolvimento predatório, expondo toda a humanidade em risco. 0 maior exemplo desse argumento é o que ocorreu na cidade de Mariana em Minas Gerais que foi devastada pela lama6.

Nas palavras de Aquino (2014), o ser humano está preocupado com sua sobrevivência no cotidiano. Ocorre que nessa dinâmica, o Outro é uma ilha distante, inal-

6 No dia 5 de novembro, precisamente às 16h20, a barragem de Fundão, em Mariana-MG, explorada pela Samarco Mineradora, que pertence à Vale e à BHP, rompeu-se, provocando danos socioambientais ainda incalculáveis. A lama com os rejeitos da mineração invadiu a localidade de Bento Rodrigues, levando, pelo leito do rio Doce, o que encontrava pela frente. Pessoas, animais silvestres e domésticos, casas, automóveis. A extensão da contaminação do Rio pela lama foi de 666 quilômetros, desaguando, finalmente, no mar. 15 pessoas foram mortas, entre crianças, adultos, idosos, entre mulheres e homens, e outras quatro estão desaparecidas. $85 \%$ das construções da localidade foram completamente destruídas (BUDÓ, 2015). 
cançável. Abandonou-se o sentido do Cuidado. Abandonou-se a capacidade de se chocar contra as atrocidades do mundo e elaborar o sentido da existência.

Portanto, é importante que todo o conhecimento científico acumulado esteja atento para a construção da Sustentabilidade Ecológica num projeto de um convívio mais justo e fraterno. Segundo Boff (2012, p. 14), "como [é possível] organizar uma aliança de cuidado para com a Terra, a vida humana e toda a comunidade de vida e assim superar os riscos referidos? A resposta: mediante a sustentabilidade, real, verdadeira, efetiva e global".

A busca de um equilíbrio sobre o uso e compartilhamento dos bens comuns não é uma atitude fácil, embora se possa compreender sua finalidade nos principais documentos internacionais. A viabilidade de um desenvolvimento proporcional somente se torna efetivo quando se observa a convergência de esforços das diferentes redes humanas, a partir daquilo que enuncia a sustentabilidade ecológica. Esse é o ponto que se visualiza como concretização das metas a ser alcançada, a exemplo da proposta que vem da América Latina, especialmente pela União de Nações Sul-Americanas (UNASUL), a qual assegura a construção harmoniosa entre homem e a natureza a partir dos diferentes ecossistemas (litosferea, hidrosfera, atmosfera e biosfera). A América Latina inova e inaugura um novo momento, pois abre o caminho da revolução paradigmática de Sustentabilidade, de matriz ecológica, na expectativa de uma justiça ecológica pautada no princípio da Solidariedade.

A partir dessa perspectiva, surgem novos conceitos pautadas para um convívio mais harmonioso, no qual humanos reconhecem os não humanos pela sua importância, pelo valor de "seres próprios", sem que haja a prevalência de juízos utilitários das pessoas para a Natureza, como se observa, ainda, no Relatório da Economia Verde do Programa das Nações Unidas ao Meio Ambiente (PNUMA). No mesmo sentido, enuncia o paradigma do Buen Vivir. Para Aquino (2016, p. 229):

A proposta do Buen Vivir restaura essa conexão entre o humano e não-humano e the fornece novo status de compreensão sobre essa totalidade incontida e dinâmica denominada Vida. A Sustentabilidade não se torna um fenômeno cuja aparência se dissocia de seu conteúdo ético, mas revitaliza-o na medida em que resgata e situa o ser humano como entidade que convive com outros seres vivos na Terra. 0 foco histórico, agora, não está na dimensão antropocêntrica, porém biocêntrica. Somos todos integrantes de uma comunidade vital capaz de se auto-organizar, autorregenerar. Somos 'um em todos e todos em um.

Esse saber ancestral andino possui um caráter ecocêntrico da relação dos humanos e não humanos, a qual favorece o cumprimento e o exercício das aproximações pretendidas. Esse reconhecimento enaltece a Pachamama como "ser próprio" e não simples objeto a ser constantemente explorado. Essa construção que precipita novos tempos, para uma Sustentabilidade compreendida na defesa dos valores próprios ou intrínsecos da Natureza e desenvolve, mais e mais, esse espaço no qual abriga todas as formas vidas, não obstante o florescer dos seres vivos, nesse jardim imperfeito, seja repleto de adversidades. Destaca Morais (2016, p. 9-31):

\begin{abstract}
Importante saber que, na confluência do dilema entre os direitos de Pachamama (da natureza) e os direitos humanos, e, perante este grande desafio dos tempos atuais, de articular e compatibilizar as macro políticas ambientais, exigências do mandato ecológico, introduzindo na constituição equatoriana, de maior preservação dos ecossistemas, com as macro políticas sociais minimizadoras das desigualdades sociais e regionais, sobretudo nos países menos desenvolvidos do Hemisfério Sul, o modelo do Bem Viver, ora em constante reconstrução, parte da crença de que não seja possível equacionar essas questões sem quem que se reveja a relação do ser humano com as forças cósmicas e telúricas, simbolizadas, respectivamente, pelo Pai Sol e pela Mãe Terra (Pachamama).
\end{abstract}

Por esse motivo, Morais (2016) entende como é importante aos seres humanos a compreensão acerca da unidade, equilíbrio, reciprocidade, respeito, complementariedade, solidariedade interespécies, cada qual com suas qualidades e possibilidades. Nenhuma vida na Terra ocorre pela eliminação do Outro. Nenhuma relação de estabilidade interespécies deve ser, na 
maior medida possível simbiótica. Enquanto a razão instrumental for o motivo para se escolher quaisquer meios a fim de satisfazer todas as nossas necessidades e se insistir caracterizar essas questões por Sustentabilidade ou as tentativas de desvelo sobre aquilo que envolve a formação da teia da vida - Desenvolvimento Sustentável - a metáfora da tragédia dos comuns de Garret continuará a afirmar que a nossa existência junto neste planeta é apenas um nome vazio.

\section{CONCLUSÃO}

Os fundamentos teóricos apresentados nesse artigo objetivaram a análise e a estruturação um modelo de Justiça Ecológica, capaz de desvelar vínculos de responsabilidade e integração entre os seres humanos e meio ambiente. Diante dos fenômenos sociais ocorridos em todo mundo nas últimas décadas, a categoria do Direito da Natureza necessita de um alcance jurídico maior, devido suas transformações no tempo, no espaço e a partir dos novos contornos delimitados pelos fenômenos de uso desmedido e irresponsável dos elementos naturais que não são, meramente, objetos destinados à utilização humana, sem qualquer forma de zelo ou comprometimento.

Primou-se, durante o processo civilizatório pelo desenvolvimento desenfreado, pelo individualismo, pelo excesso do consumo e de acúmulo de riquezas, dentre outros. Este cenário atendeu aos anseios progressistas e ao bem-estar do homem, mas, por outro lado, tornou-se um desvio civilizatório na jornada humana e transformou o consumo em um ciclo vicioso. Isso não produziu a experiência da alegria, na cidadania. Para atingir o desenvolvimento almejado, o homem utilizou o mundo natural com voracidade durante séculos.

Diante da finitude dos elementos naturais, a vida terrena tornou-se insustentável. Como possibilidade de superação desta crise, é proposta uma nova forma de relacionar natureza e humanidade, por meio do paradigma da sustentabilidade. Este princípio norteador das ações humanas concretiza a manutenção de um ecossistema saudável e equilibrado, com vistas nas gerações que ainda estão por vir, em processos de inter-reciprocidade.

A despeito de crescer a todo o custo, o importante, quando se pensa em sustentabilidade, é ultrapassar a visão desenvolvimentista por outro olhar, o de proteção ao meio ambiente. Esta é uma ação de responsabilidade imprescindível junto aos segmentos norteadores dos direitos humanos.

Todos os problemas que se apresentam em níveis diferentes de agravamento ao ambiente natural precisam ser debatidos na sociedade, de modo que seja construída uma inteligência coletiva que compreenda a crise ambiental como uma crise civilizatória.

Um projeto de direito da natureza requer uma compreensão ética, destacando os valores fundamentais da vida, de modo a preservar o lugar de todos os seres. A exigência de cuidar é uma necessidade de vida que busca guardar a vida em confronto com os esforços de destruição.

A sustentabilidade, quando vivenciada pelo homem, pode ser um caminho viável para diminuir o risco da finitude da vida humana na terra. Para tanto, além do exercício dos direitos políticos, estrutura-se uma nova dimensão dos direitos humanos ecológicos, cujo critério de união é a ecologia.

Os direitos humanos efetivos a condição de "Estar Junto" com o "Outro", a partir de um compromisso assumido pelos cidadãos na busca de uma sociedade sustentável. 0 meio ambiente, como critério de união dos seres que habitam esse Planeta é capaz de transnacionalizar categorias jurídicas, desde que haja um núcleo social preparado para as mudanças que estão por vir. Dessa forma, concretiza-se uma justiça ecológica, por meio da ética e da responsabilidade, de modo a apresentar respostas concretas à crise ecológica contemporânea, em prol do bem comum mundial.

\section{REFERÊNCIAS}

ACOSTA, Alberto. 0 buen vivir. Uma oportunidade de imaginar outro mundo. Disponível em: <http:// 
br.boell.org/sites/default/files/downloads/alberto_ acosta.pdf>. Acesso em: 24 abr. 2017.

AQUINO, Sérgio Ricardo Fernandes de. 0 direito em busca de sua humanidade: diálogos errantes. Curitiba: CRV, 2014.

AQUINO, Sérgio Ricardo Fernandes de. Raízes do direito na pós-modernidade. Itajaí, SC: UNIVALI, 2016.

ARISTÓTELES. Ética a Nicômaco. Tradução de Mário da Gama Cury. 3.ed. Brasília: UNB, 1999.

ARIZIO, Silvia Helena. Manifesto para uma justiça ecológica: sua importância acerca do direito das águas. Erechim: Deviant, 2017.

BOFF, Leonardo. A grande transformação: na economia, na política e na ecologia. Petrópolis, RJ: Vozes, 2014.

BOFF, Leonardo. Sustentabilidade: o que é - o que não é. Petrópolis, RJ: Vozes, 2012.

BODNAR, Zenildo; CRUZ, Paulo Márcio. 0 acesso à justiça e as dimensões materiais da efetividade da jurisdição ambiental. Revista Pensar, Fortaleza, v.17, n.1, p.318-346, jan-jun. 2012. Disponível em: <http:// ojs.unifor.br/index.php/rpen/article/viewFile/2293/ pdf>. Acesso 27 abr. 2017.

BOLIVIA. Conferência Mundial dos Povos sobre Mudanças Climáticas e Direitos de Pacha Mama. Declaração Universal dos Direitos da Mãe Terra. Cochabamba. 2010. Disponível em: <http:// revolucoes.org.br/v1/sites/default/files/matdidatico/ Declara\%C3\%A7\%C3\%A30\%20Universal\%20 dos\%20Direitos\%20da\%20M\%C3\%A3e\%20Terra. pdf >. Acesso em: 5 maio 2017.

\section{BOSSELMANN, Klaus. 0 princípio da}

sustentabilidade: transformando direito e Governança. Tradução Philip Gil França. São Paulo: Revista dos Tribunais, 2015.
BOSSELMAN, Klaus. Direito humanos, meio ambiente e sustentabilidade. In: SARLET, Ingo Wolfgang. Estado Sociaambiental e direitos fundamentais. Porto Alegre: Livraria do Advogado, 2010.

BUDÓ, Marília de Nardin. Isolar o fato e pôr a culpa nos astros: o plano de fuga perfeito. Revista $\mathbf{O}$ Viés jornalismo a contrapelo. Coluna, 16 de dezembro de 2015. Disponível em: <www.revistaovies.com>. Acesso em: 18 dez 2016.

\section{GUSSOLI. Felipe Klein. A natureza como sujeito de} direitos na Constituição do Equador: considerações a partir do caso Vilacamba. Disponível em: <www. direito.ufpr.br/.../anais-da-xvi-jornada-de-iniciacaocientifica-vol-1>. Acesso em: 30 out. 2017.

GRIMM, Dieter. A função protetiva do Estado. Tradução Eduardo Mendonça. In: SOUZA NETO, Cláudio Pereira de; SARMENTO, Daniel (Coord.). A constitucionalização do direito: fundamentos teóricos e aplicações específicas. Rio de Janeiro: Lumen Juris, 2007.

LOURENÇO, Daniel Braga; OLIVEIRA, Fábio Corrêa Souza de. Sustentabilidade Insustentável? In: FLORES, Nillton Cesar. A sustentabilidade ambiental: em suas múltiplas faces. Campinas: Millennium, 2012.

MORAES. Germana de Oliveira. 0 constitucionalismo ecocêntrico nos Andes: os direitos de Pachamama, o bem viver e o direito à água. In: MORAES, Germana de Oliveira; GARCIA, Marcos Leite; UNNEBERG, Flávia Soares. Para além das fronteiras: o tratamento jurídico das águas na UNASUL. Parte I, vol. 2, Itajaí: Univali. 2012. Disponível em: <http://www.univali.br/ppcj/ebook>. Acesso em: 26 abr. 2017.

MORIN, Edgar. Para onde vai o mundo? Tradução: Francisco Morás. 2.ed. Petrópolis, RJ: Vozes, 2010. 
PASOLD, Cesar Luiz. Metodologia da pesquisa

jurídica: teoria e prática. 12.ed. Florianópolis:

Conceito Editoria/Millenium, 2011.

PELLENZ, Mayara. Cidadania e educação ambiental: novas perspectivas a partir da Transnacionalidade. Erechim: Deviant, 2015.

\section{SAMPAIO, Marcos. 0 conteúdo essencial dos}

direitos sociais. São Paulo: Saraiva, 2013.

\section{SARLET, Ingo Wolfgang. Dignidade da pessoa} humana e direitos fundamentais na constituição de

1988. Porto Alegre: Livraria do Advogado, 2006.
SHIVA, Vandana. Le guerre dell'acqua. Tradução

Bruno Amato. Milano: Giangiacomo Feltrinelli, 2010.

WOLKMER, Maria de Fátima. O desafio ético da água comum um direito humano. In: WOLKMER, Antonio Carlos et al. Para além das fronteiras: o tratamento jurídico das águas na UNASUL. Itajaí: UNIVALI, 2012, p.46-60. Disponível em: <http://www.univali.br/ppcj/ ebook>. Acesso em: 4 maio 2017.
Recebido em: 18 de outubro de 2017

Avaliado em: 28 de julho de 2018 Aceito em : 29 de julho de 2018

\begin{abstract}
1 Mestre em Direito, Democracia e Sustentabilidade pelo Programa de Pós-Graduação da Faculdade Meridional; Pós-graduada em Direito Penal e Processo Penal e em Psicologia Jurídica na Faculdade Meridional; Graduada em Direito pela Universidade de Passo Fundo - RS; Associada ao Conselho Nacional de Pós-Graduação em Direito. Docente Titular do Curso de Direito da UNISOCIESC de Blumenau - SC; Docente do Curso de Pós Graduação em Direito da Faculdade AVANTIS de Balneário Camboriú - SC; Docente do Curso de Pós Graduação em Psicologia Jurídica da Universidade Alto Vale do Rio do Peixe de Caçador - SC; Pesquisadora dos Grupos de Pesquisa: Ética, Cidadania e Sustentabilidade e Multiculturalismo e Pluralismo Jurídico, desenvolvidos na Faculdade Meridional de Passo Fundo - RS e do Grupo de Pesquisa Direito Empresarial e Sustentabilidade da UNISOCIESC de Blumenau - SC; Advogada. E-mail: maypellenz@hotmail.com

2 Doutoranda em Direito pela Universidade Regional Integrada do Alto do Uruguai e das Missões - URI / campus de Santo Ângelo; Mestra em Direito, Democracia e Sustentabilidade pela Faculdade Meridional - IMED (bolsista Capes); Mestranda em Direito pela Universidade de Passo Fundo - UPF (bolsista UPF); Especialista em Direito Processual Civil e Direito do Trabalho e Processo do Trabalho pela Faculdade Meridional - IMED; Especialista em Direito Notarial e Registral, Direito Previdenciário, Direito Civil e Direito Empresarial e Advocacia Empresarial pela Universidade Anhanguera Uniderp; Integrante do Grupo de Pesquisa Multiculturalismo e Pluralismo Jurídico e do Grupo de Pesquisa Ética, Cidadania e Sustentabilidade, desenvolvidos na Faculdade Meridional - IMED; Pesquisadora do Grupo de Pesquisa Jurisdição Constitucional, desenvolvido na Universidade de Passo Fundo - UPF; Oficiala de Registro. E-mail: rafaela_baldissera@hotmail.com
\end{abstract}

